\title{
Conditioned reinforcement: The effects of variation of stimulus duration
}

\author{
MARY LOU CHEAL and RICHARD L. SPROTT, Oakland \\ University, Rochester, Michigan 48063
}

Sixteen albino rats were trained with simultaneous presentation of light and food reinforcement. The duration of light was varied from 0.0 to $10.0 \mathrm{sec}$. Later ability to learn a new response, bar press, was used to test the strength of the conditioned stimulus. Bar presses produced light in varying durations according to $a 4$ by 4 factorial c'esign. The results showed that the effect of simultaneous light-food pellet training was to strengthen the new response, but failed to lend any support to a discrimination hypothesis. Conclusions allowed some room for the facilitation hypothesis but favored the conditioned reinforcement concept.

A neutral stimulus which is associated with a reinforcing stimulus will become a conditioned reinforcer so that it takes on the characteristics of a reinforcing stimulus. At least three hypotheses have been posed to explain this phenomenon. Proponents of the discrimination hypothesis state that it is merely the similarity between conditions of training and conditions of testing which yields an increment in responding (e.g., Bitterman, Fedderson, \& Tyler, 1953; Elam, Tyler, \& Bitterman, 1954). Proponents of the facilitation hypothesis (Wyckoff et al, 1958) state that any stimulus event merely keeps the animal in the vicinity of the bar, thus increasing the probability that the bar will be pressed. On the other hand, a growing body of evidence (e.g., Skinner, 1938; Saltzman, 1949; Kelleher, 1961) supports Kelleher's contention that the concept of conditioned reinforcement offers the most complete and parsimonious explanation of the data. For a complete review of conditioned reinforcement see Kelleher \& Gollub (1962).

In an early investigation of the conditioned reinforcement problem Bersh (1951) systematically varied the duration of light presented to rats prior to the presentation of food reinforcement (from 0.0 to $10.0 \mathrm{sec}$ ) and measured the effect of such variation upon the acquisition by the neutral stimulus of the power to reinforce a previously untrained operant: the rate of bar pressing to produce the light. The highest rate of responding was made by the $0.5 \mathrm{sec}$ and $1.0 \mathrm{sec}$ light duration groups with the $10.0 \mathrm{sec}$ duration group responding at a significantly lower rate than the shorter duration groups. Bersh leaned towards a conditioned reinforcement explanation of his results.

However, Myers (1958) noted that all of Bersh's groups received the light for $1.0 \mathrm{sec}$ during test sessions, so that there was greatest similarity between training and test sessions for the $1.0 \mathrm{sec}$ training group. He suggested a discrimination viewpoint as an explanation for the greater response rate for the $1.0 \mathrm{sec}$ group (although Bersh's results do not show this to be significant).

To test the discrimination hypothesis the present experiment equated the duration of the light during training and testing, presenting light and food pellets contiguously. In this way the neutral stimulus was not established as a discriminative stimulus. It was also possible to test the effect of simultaneous pairing of the reinforcing stimulus and the neutral stimulus in comparison with a control group which did not receive the neutral stimulus, in order to determine the strength of the conditioned stimulus.

\section{METHOD}

Sixteen naive, male, albino, Wistar derived rats from 65 to 80 days old, drawn from the Oakland University colony, were used as Ss. In order to establish a hunger rythm, Ss were given $45 \mathrm{~min}$ access to food and $23 \frac{1}{4} \mathrm{~h}$ of deprivation each day for three successive days. On Day 4, after $23 \mathrm{~h}$ of food deprivation, each rat was placed in an operant conditioning chamber (Scientific Prototype Mfg. Corp., Model H-110) to determine the spontaneous bar press in a situation with no correlated stimulus change or reinforcement. The chamber was provided with a $6 \mathrm{~W}$ cue light, and all trials were run in a darkened room.

On Days 5 and 6, a 10 min pretest measured the number of bar presses with no food reinforcement. Each bar press produced the appropriate duration of light (Group A, no light; Group B, 0.5 sec light; Group C, $1.0 \mathrm{sec}$ light; Group D, 10.0 sec light). On Days 7 through 10 , the bar was covered and food pellets were released one at a time. After the first 10 pellets, each pellet was paired with the apuropriate duration of light, 70 pairing in all. A 4 by 4 factorial design was used to determine the duration of the light for this training (see Table 1).

On Days 11 and 12, Ss were tested using exactly the same procedure as that used in the pretest. Pretest bar presses (Days 5 and 6) were subtracted from the test bar presses to give the experimental data.

\section{RESULTS}

A comparison of the seven control conditions in which Ss had no light in training or no light in testing with the nine experimental conditions revealed a significant increase in responding during testing $(\mathrm{p}<.01,1$-tailed; Mann-Whitney $U$ Test, Siegel, 1956) when Ss were both trained and tested with light. Ss in the nine conditions which were trained with light showed a significantly greater increase in responses than Ss in the three conditions which were trained with no light $(\mathrm{p}<.001,1$-tailed $)$.

No significant differences were found in the following comparisons: Ss trained using $0.5 \mathrm{sec}$ light with Ss trained using $10.0 \mathrm{sec}$ light; performance of all Ss before training with their performance after training; Ss receiving the same stimulus duration during training and testing with $\mathrm{Ss}$ receiving different stimulus durations.

Table 1

Summary of Procedures and Results

\begin{tabular}{|c|c|c|c|c|c|c|c|}
\hline \multirow{3}{*}{$\frac{\text { Training }}{\text { No Light }}$} & \multicolumn{7}{|c|}{ Testing } \\
\hline & No Light & & $0.5 \mathrm{sec}$ & & $1.0 \mathrm{sec}$ & & $10.0 \mathrm{sec}$ \\
\hline & $\begin{array}{l}\text { Test } \\
\text { Pretest } \\
\text { Difference }\end{array}$ & $\begin{array}{l}2 \\
2 \\
0\end{array}$ & $\begin{array}{l}\text { Test } \\
\text { Pretest } \\
\text { Difference }\end{array}$ & $\begin{array}{l}26 \\
30 \\
-4\end{array}$ & $\begin{array}{l}\text { Test } \\
\text { Pretest } \\
\text { Difference }\end{array}$ & $\begin{array}{r}0 \\
1 \\
-1\end{array}$ & $\begin{array}{l}\text { Test } \\
\text { Pretest } \\
\text { Difference- }\end{array}$ \\
\hline $0.5 \mathrm{sec}$ & $\begin{array}{l}\text { Test } \\
\text { Pretest } \\
\text { Difference }\end{array}$ & $\begin{array}{l}0 \\
0 \\
0\end{array}$ & $\begin{array}{l}\text { Test } \\
\text { Pretest } \\
\text { Difference }\end{array}$ & $\begin{array}{l}6 \\
2 \\
4\end{array}$ & $\begin{array}{l}\text { Test } \\
\text { Pretest } \\
\text { Difference }\end{array}$ & $\begin{array}{l}2 \\
0 \\
2\end{array}$ & $\begin{array}{l}\text { Test } \\
\text { Pretest } \\
\text { Difference }\end{array}$ \\
\hline $1.0 \mathrm{sec}$ & $\begin{array}{l}\text { Test } \\
\text { Pretest } \\
\text { Difference }\end{array}$ & $\begin{array}{l}0 \\
0 \\
0\end{array}$ & $\begin{array}{l}\text { Test } \\
\text { Pretest } \\
\text { Difference }\end{array}$ & $\begin{array}{l}12 \\
16 \\
-4\end{array}$ & $\begin{array}{l}\text { Test } \\
\text { Pretest } \\
\text { Difference }\end{array}$ & $\begin{array}{l}1 \\
1 \\
0\end{array}$ & $\begin{array}{l}\text { Test } \\
\text { Pretest } \\
\text { Difference }\end{array}$ \\
\hline $10.0 \mathrm{sec}$ & $\begin{array}{l}\text { Test } \\
\text { Pretest } \\
\text { Difference }\end{array}$ & $\begin{array}{l}2 \\
2 \\
0\end{array}$ & $\begin{array}{l}\text { Test } \\
\text { Pretest } \\
\text { Difference }\end{array}$ & $\begin{array}{l}36 \\
10 \\
26\end{array}$ & $\begin{array}{l}\text { Test } \\
\text { Pretest } \\
\text { Difference }\end{array}$ & $\begin{array}{l}3 \\
1 \\
2\end{array}$ & $\begin{array}{l}\text { Test } \\
\text { Pretest } \\
\text { Difference }\end{array}$ \\
\hline
\end{tabular}




\section{DISCUSSION}

Bersh (1951) asks if the key process in establishing a neutral stimulus as a conditioned stimulus is elicitative control over respondents or of discriminative control over operants. To test the discrimination hypothesis, in the present experiment the onset of light was simultaneous with the presentation of the food reinforcement so that the light could not become a discriminative stimulus. If the light became a conditioned reinforcement then the Ss would acquire the new response of bar press. Wyckoff et al (1958) defined discriminative effects of a stimulus as the changes in the rate of response in the presence of the stimulus while conditioned reinforcing effects of a stimulus are the changes in the rate of response preceding the stimulus. The present experimental design tested only for conditioned reinforcing effects. Simultaneous pairing was effective in yielding an increment in responses as seen by the higher rate performance of experimental Ss in comparison with the performance of control Ss.

Kelleher \& Gollub (1962) ask if the duration of the stimulus presentation is relevant. If the duration of the stimulus presentation were relevant, Ss trained and tested with the same light duration should have shown the highest rate of response. As there was no significant difference between Ss with the same duration of light and those with different durations of light in training and testing, the discrimination hypothesis appears inappropriate.

Further, no difference in performance was observed between Ss trained with $0.5 \mathrm{sec}$ light and Ss trained with 10.0 sec light. This observation lends additional support to a conditioned reinforcement concept.

The facilitative hypothesis of Wyckoff et al (1958) also casts doubt on the discrimination hypothesis and the general concept of secondary reinforcement. Myers (1958) suggests that the stimulus must be discriminative to be established as a secondary reinforcer, as it then keeps $S$ in the vicinity of the bar and keeps $S$ active. The present study shows that the neutral stimulus does obtain reinforcing properties without being established as a discriminating stimulus but this may be facilitative as the food tray was next to the bar press and $S$ did tend to stay in this area.
Kelleher \& Gollub (1962) state that a stimulus to be established as a conditioned reinforcer need not be originally neutral. As long as the data measures the differences before and after training as a conditioned reinforcer, it is possible to determine the strength of the reinforcement due to that training. As a light may be a weak positive reinforcer before training, it is probably better to gather data by comparing responses before and after training than by comparing responses of matched groups as did Bersh (1951).

In conclusion, it would seem that the discrimination hypothesis cannot explain the present results. The facilitation hypothesis may account for part of the results. However, the conditioned reinforcement concept seems to offer the most satisfactory integration of the available evidence (Kelleher \& Gollub, 1962).

\section{REFERENCES}

BERSH, P. J. The influence of two variables upon the establishment of a secondary reinforcer for operant responses. Journal of Experimental Psychology, 1951, 41, 62-73.

BITTERMAN, M. E., FEDDERSON, W. E., \& TYLER, D. W. Secondary reinforcement and the discrimination hypothesis. American Journal of Psychology, 1953, 66, 456-464.

ELAM, C. B., TYLER, D. W., \& BITTERMAN, M. E. A further study of secondary reinforcement and the discrimination hypothesis. Journal of Comparative \& Physiological Psychology, 1954, 47, 381-384.

KELLEHER, R. T. Schedules of conditioned reinforcement in experimental extinction. Journal of the Experimental Analysis of Behavior, 1961, 4, 1-5.

KELLEHER, R. T., \& GOLLUB, L. R. A review of positive conditioned reinforcement. Journal of the Experimental Analysis of Behavior, $1962,5,4,543-597$.

MYERS, J. L. Secondary reinforcement: a review of recent experimentation. The Psychological Bulletin, 1958, 55, 284-301.

SALTZMAN, I. J. Maze leaming in the absence of primary reinforcement: a study of secondary reinforcement. Journal of Comparative \& Physiological Psychology, 1949, 42, 161-173.

SIEGEL, S. Nonparametric statistics for the behavioral sciences. New York: McGraw-Hill Book Co., 1956.

SKINNER, B. F. The behavior of organisms: An experimental analysis. New York: Appleton-Century, 1938.

WYCKOFF, L. B., SIDOWSKI, J., \& CHAMBLISS, D. J. An experimental study of the relationship between secondary reinforcing and cue effects of a stimulus. Journal of Comparative \& Physiological Psychology, 1958, 51, 103-109. 